6. McMartin K., Jacobsen D, Hovda K.E, et al (2016). Antidotes for poisoning by alcohols that form toxic metabolites. $\mathrm{Br} \mathrm{J}$ Clin Pharmacol; 81(3):505-15.

7. Wedge M.K., Natarajan S., Johanson $C_{\text {., }}$ et al (2012). The safety of ethanol infusions for the treatment of methanol or ethylene glycol intoxication: an observational study. CJEM; 14(5):283-9

8. Zakharov S., Nurieva O., Kotikova K., et al (2017). Positive serum ethanol concentration on admission to hospital as the factor predictive of treatment outcome in acute methanol poisoning. Monatsh Chem, 148(3):409-419.

\title{
ĐIỀU TRI BÓC TÁCH ĐộNG MẠCH CHỦ CẤP TÍNH BẰNG PHẪU THUÂTT MỞ KẾT HỢP ỐNG GHÉP LAI
}

\section{TÓM TẮT.}

Đăt vấn đề: Bóc tách động mạch chủ ngực cấp tính là một cấp cứu tim mạch nguy cơ cao, đặc biệt là thể lâm sàng Stanford A- De Bakey I. Bên cạnh phẫu thuật mổ mở kinh điển, phẫu thuật hybrid (mổ mở kết hợp đặt ống ghép lai) là phương pháp giải quyết thêm thương tổn ở động mạch chủ xuống. Tuy nhiên, cần có nghiên cứu hiệu quả của phương pháp này. Phương pháp nghiên cứu: Hồi cứu các trường hợp phẫu thuật mổ mở kết hợp đặt ống ghép lai nội mạch đông mach chủ từ tháng $5 / 2020$ đến tháng 9/2020 tai khoa Hổi sức- Phẫu thuật Tim BVCR với chẩn đoán trước mổ là phình lóc đô̂ng mach chủ ngực cấp tính loại Stanford A - De Bakey I. Kết quả: Có 17 bệnh nhân trong nghiên cứu, nam/nữ $=13 / 4$. Tuổi trung bình $56,5 \pm 12,7$. Phân suất tống máu thất trái trước mổ $E F=63 \pm 3,9 \%$. Đường kính động mach chủ lên trung bình: 43,2 $\pm 1,8 \mathrm{~mm}$, tỷ lệ đường kính động mạch chủ ngức lên/diên tích da cơ thể là $24,14 \mathrm{~mm} / \mathrm{m}^{2}$ da. Thời gian kẹp động mạch chủ $118 \pm 39$ phút và thời gian chay máy là $220 \pm 30$ phút. Số lượng ống ghép đặt cho một bệnh nhân là 1 , chiều dài ống ghép: $175,7 \pm 16 \mathrm{~mm}$. Tỷ lệ tử vong là $2 / 17(11,7 \%)$. Kết luận: Phẫu thuật mổ mở kết hợp đặt ống ghép lai sản xuất tại chỗ là hiệu quả, điều trị tốt các trường hợp bệnh động mạch chủ bóc tách cấp tính Stanford ADeBakey I. Phương pháp này có thể nhân rộng cho các trung tâm tim mạch khác.

Tư khoá: bóc tách động mạch chủ, ông ghép lai, stentgraft

\section{SUMMARY}

\section{ROLE Of HYBRID PROTHESIS IN TREATMENT OF ACUTE STANFORD A-DE BAKEY I AORTIC DISSECTION}

Objectives: Acute aortic dissection is one of the most serious cardiovascular emergencies, especially the Stanford A - De Bakey I one. Beside the conventional approach, hybrid surgery (modified

*Trung tâm Tim mạch, Bệnh viện Chợ Rẫy Chịu trách nhiệm chính: Nguyễn Thái An Email: nthaian@yahoo.com Ngày nhận bài: 4.01.2021 Ngày phản biên khoa học: 26.2.2021 Ngày duyệt bài: 9.3.2021

\section{Nguyễn Thái An*, Trần Quyết Tiến*}

frozen elephant trunk technique) is considered to be an efficient solution for damages in descending aorta. However, it is necessary to conduct a research about the efficacy of this kind of surgery. Subject and method: We have reviewed retrospectively all the cases that had pre-operative diagnosis as Stanford De Bakey I aortic dissection and were treated by using hybrid surgery from 5/2020 to 9/2020 at Cardiac CareSurgery department of Cho Ray Hospital. Results: There are 17 patients in the study, 13 males and 4 females, whose average are is $56,5 \pm 12,7$. The preoperative left ventricular ejection fraction (EF) is $63 \pm 3,9 \%$. The average diameter of ascending aorta is $43,2 \pm 1,8 \mathrm{~mm}$ and the rate ascending aortic diameter/body surface is $24,14 \mathrm{~mm} / \mathrm{m}^{2}$. The clamping time is $118 \pm 39$ minutes and the time of extracoporeal circulation is $220 \pm 30 \mathrm{~min}$. The number of grafts for one patient is one, and the length is $175,7 \pm 16 \mathrm{~mm}$. The mortality is $2 / 17(11,7 \%)$. Conclusion: The hybrid surgery (modified frozen elephant trunk technique) is an effective solution and stronglyrecommeneded for the cases of Acute Stanford ADeBakey I aortic dissection. This approach can be transferred to other cardiac centers in Vietnam.

Keyword: Aortic dissection, hybrid prothesis, stentgraft.

\section{I. ĐẶT VẤN ĐỀ}

Bóc tách động mach chủ cấp tính kiểu $A$ theo phân loại Stanford (gọi tắt là Stanford $\mathrm{A}$ ) là một bệnh lý nặng nề với tỳ lệ tử vong cao, 12-19,8\% [1], [2]. Trong các trường hợp bóc tách Stanford A kéo dài đến động mạch chủ bunng, tức là kiểu I theo phân loại De Bakey (gọi tắt là De Bakey I), phẫu thuật càng phức tạp vì vừa phải giải quyết bệnh lý của động mạch chủ đoạn lên và quai đồng thời phải làm tăng lượng máu tưới các tạng trong ổ bụng. Để giải quyết vấn đề tưới máu tạng trong ố bụng, hiện nay, có nhiều phương pháp như: kỹ thuật vòi voi kinh điển, kỹ thuật vòi voi kèm stentgraft (frozen elephant trunkFET), kỹ thuật mổ mở kết hợp đặt giá đõ Ascyrus [3]. Tuy nhiên, chúng tôi sử dụng kỹ thuật mố mở với ống ghép lai để giải quyết vấn đề của động mạch chủ ngực xuống. Nghiên cứu 
này nhằm báo cáo kết quả sớm của kỹ thuật mổ mở với ống ghép lai.

\section{II. ĐỐI TƯợNG VÀ PHƯƠNG PHÁP NGHIÊN CỨU}

Hồi cứu mô tả các bệnh nhân có chẩn đoán bóc tách cấp tính động mạch chủ Stanford $A$, DeBakey I được phấu thuật bằng kỹ thuật mố mở với ống ghép lai trong thời gian tháng 5/2020 đến 9/2020 tại khoa Hồi sức- Phẫu thuật Tim bệnh viện Chợ Rẩy.

Phương pháp phẫu thuật

Sau khi bệnh nhân được chẩn đoán xác định bằng chụp cắt lớp điện toán 64 dãy có tiêm thuốc cản quang, tiến hành đo đường kính động mạch chủ ngực xuống và chọn ống ghép nội mạch (stentgraft) Valiant miếng phụ (Medtronic) có đường kính đầu xa bằng với trị số đo được hoăc lớn hơn không quá $10 \%$, chiều dài stent khổng vượt quá bờ dưới thân đốt sống ngực 10. Đầu gần của ống ghép có thể bằng hoặc lớn hơn đầu xa.

Cách tạo ống ghép tại chỗ (hình 1 cà hình 2):

Trong môi trường phòng mổ, bung 1 mắc stent, cắt các khung kim loại. Chú ý không làm thủng phần ống ghép. Như vậy, ống ghép lai có 2 phần: phần thứ nhất là đoạn graft thông thường có chiều dài là $15-18 \mathrm{~mm}$ tùy theo kích thước stentgraft đã chọn. Phần thứ hai là đoạn stentgraft còn lại. Nhét phần thứ nhất vào trở lại sheath của stentgraft như ban đầu.

Phương pháp phẫu thuật (hình 3, hình 4):

Bệnh nhân nằm ngửa, mở ngực đường giữa toàn xương ức, thiết lập máy tuần hoàn ngoài cơ thể như thay quai động mạch chủ. Trong khi hạ thân nhiệt, đặt ống thông pigtail từ đùi bên đã chọn đường vào để đặt ông ghép. Dùng siêu âm trực tiếp động mach chủ ngực xuống hoặc qua ngã thực quản để đảm bảo rằng pigtail đã nằm trong lòng thật động mạch chủ ngực xuống. Kẹp động mạch chủ ngực lển, cắt ngang động mạch chủ ngực lên, bơm dung dịch liệt tim bảo vệ tim. Ngưng tuần hoàn khi nhiệt độ đủ, phẫu tích vùng quai động mạch chủ và nuôi não chọn lọc thuận chiều. cắt quai động mạch chủ ở vùng 2 hoặc 3 tương ứng lỗ vào ở đoạn động mạch chủ lên hoặc quai. Nếu lỗ vào ở đoạn xuống, cắt động mạch chủ ngang vùng 3 hoặc 4 . Đặt ống ghép lai ngược dòng theo pigtail, bung ông ghép sao cho mép của ống ghép trùng với đường cắt động mạch chủ. Đính đoạn graft của ống ghép lai vào thành động mạch chủ. Thực hiện miệng nối xa: khâu nối ống mạch máu nhân tạo thường quy với ống ghép lai và thành động mạch chủ có miếng đệm bằng PTFE. Tưới máu lại phần xa động mạch chủ. Làm ấm dần. Thực hiện miệng nối gần: khâu nối mạch máu nhân tạo với đầu gần động mạch chủ lển. Mở kẹp động mạch chủ cho tim đập lại. Tái tạo lại các nhánh động mạch tầng trên quai động mạch chủ.

\section{KẾT QUẢ NGHIÊN CỨU}

Bảng 1. Đặc điểm bệnh nhân

\begin{tabular}{|c|c|c|}
\hline Đặc điểm & $\begin{array}{c}\text { Số lượng } \\
(\mathrm{n}=17)\end{array}$ & $\%$ \\
\hline Giới tính: Nam & $\begin{array}{c}13 \\
4\end{array}$ & $\begin{array}{l}76,5 \\
23,5\end{array}$ \\
\hline $\begin{array}{l}\text { Nữ } \\
\text { Tuối }\end{array}$ & $\frac{4}{56,5 \pm 12,7}$ & \\
\hline Đau ngực khi vào viện & 17 & 100 \\
\hline $\begin{array}{l}\text { Giảm tưới máu cơ quan } \\
\text { đích trên CT scan }\end{array}$ & 17 & 100 \\
\hline Tràn máu màng ngoài tim & 10 & 58,9 \\
\hline EF trước mố (\%) & $63 \pm 3,9$ & \\
\hline $\begin{array}{l}\text { Đường kính động mạch } \\
\text { chủ ngực đoạn lên }(\mathrm{mm})\end{array}$ & $43,2 \pm 1,8$ & \\
\hline Bệnh kèm theo & & \\
\hline $\begin{array}{l}\text { Tăng huyết áp } \\
\text { Rối loan chuyển hóa mõ }\end{array}$ & $\begin{array}{l}17 \\
17\end{array}$ & $\begin{array}{l}100 \\
100\end{array}$ \\
\hline Tiểu đường & 5 & 29,5 \\
\hline
\end{tabular}

Bảng 2. Đặc điếm phấu thuật và kêt quả sau mố

\begin{tabular}{|c|c|c|}
\hline Đặc điểm & $\begin{array}{c}\text { Số } \\
\text { lượng } \\
(n=17)\end{array}$ & $\%$ \\
\hline Thời gian chạy máy (phút) & $220 \pm 30$ & \\
\hline $\begin{array}{l}\text { Thời gian kẹp đống mạch chủ } \\
\text { (phút) }\end{array}$ & $118 \pm 39$ & \\
\hline $\begin{array}{l}\text { Thời gian không tưới máu đoạn } \\
\text { xa động mạch chủ (phút) }\end{array}$ & $55 \pm 10$ & \\
\hline $\begin{array}{l}\text { Thời gian tưới máu não chọn } \\
\text { lọc (phút) }\end{array}$ & $120 \pm 10$ & \\
\hline $\begin{array}{l}\text { Phấu thuật gốc động mạch chủ } \\
\text { kèm theo (bệnh nhẩn) }\end{array}$ & 3 & 17,7 \\
\hline $\begin{array}{l}\text { Phấu thuật bắc cầu mạch vành } \\
\text { kèm theo (bệnh nhân) }\end{array}$ & 2 & 11,7 \\
\hline $\begin{array}{c}\text { Chảy máu cân phải mố lại } \\
\text { (bệnh nhân) }\end{array}$ & 0 & 0 \\
\hline Lọc máu sau mố (bệnh nhân) & 0 & 0 \\
\hline $\begin{array}{l}\text { Biến chứng thân kinh vĩnh viến } \\
\text { (bệnh nhân) }\end{array}$ & 0 & 0 \\
\hline $\begin{array}{l}\text { Tử vong sau mố (bệnh nhân) } \\
\text { Liên quan với động mach chủ } \\
\text { Không liên quan với động mạch } \\
\text { chủ: choáng nhiếm trùng }\end{array}$ & $\begin{array}{l}0 \\
2\end{array}$ & $\begin{array}{c}0 \\
11,7\end{array}$ \\
\hline Chiều dài ống ghép lai (mm) & $175 \pm 16$ & \\
\hline $\begin{array}{l}\text { Huyết khối hoàn toàn lòng giả } \\
\text { hoặc lòng thâat nở hoàn toàn } \\
\text { (bệnh nhân) }\end{array}$ & 17 & 100 \\
\hline
\end{tabular}




\section{BÀN LUẬN}

Uu điểm của phương pháp mổ:

- Lần đầu tiên báo cáo tại Việt Nam với số lượng hang loạt ca.

- Không dùng tia $X$, và không dùng thuốc cản quang nên giảm thiểu các nguy hại cho bệnh nhân, nhất là chức năng thân vốn dĩ rất dễ tổn thương do phải chạy máy kéo dài vì mổ phức tạp

- Cuộc mổ không bị gián đoạn để đưa máy chiếu tia $X$ so với phương pháp hybrid đặt stentgraft

- Không bị biến chứng di chuyển ống ghép lai trong tương lai, vì ống ghép này đã khâu đính vào thành động mạch chủ

- Không có endoleak type IA vì ống ghép lai được cố định bằng chỉ khâu

- Kết quả trong vòng 30 ngày là có thể so sánh với kết quả tử vong của các nước trên thế giới như Mỹ, Nhật (11,7\% vs 12-19,8\% [2] [1])

- Tiết kiệm đáng kể chi phí cho bệnh nhân vì ống ghép lai tự làm có giá thành thấp hơn các stentgraft trên thị trường

Khuyết điểm:

- Kéo dài thời gian không tưới máu phần xa của động mạch chủ. Tuy nhiên thời gian này là thời gian đặt và bung ống ghép lai, có thể rút

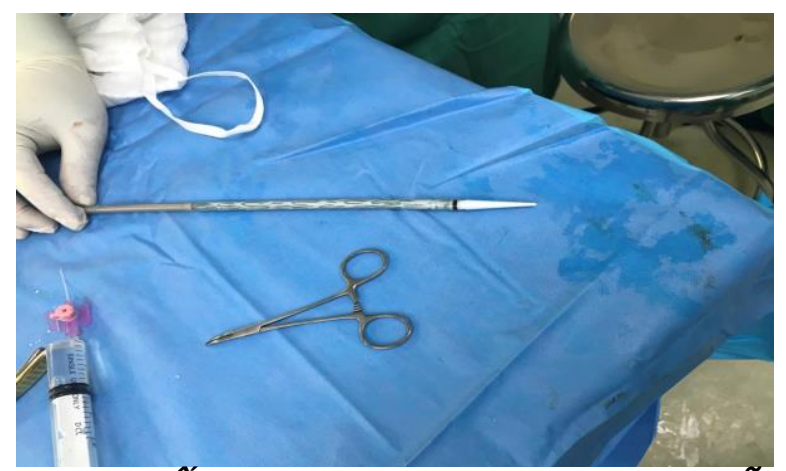

Hình 2. Ông ghép lai đã "sản xuất" tại chố.

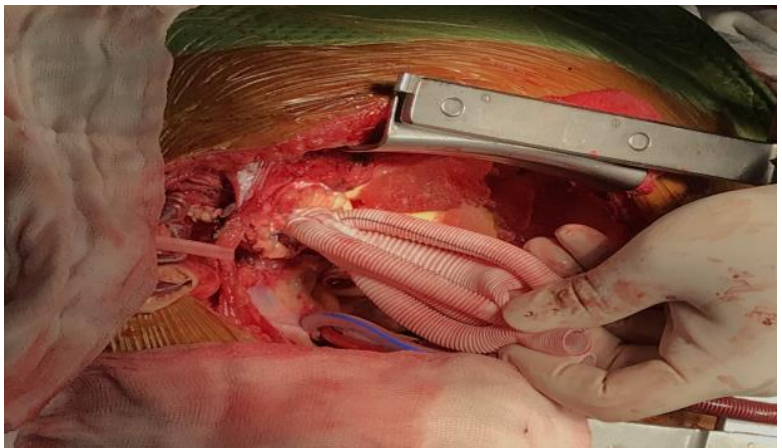

Hình 4. Miệng nôi xa động mạch chủi ống ghép lai, động mạch chủ, mạch máu nhân tạo thường quy được khâu chung. ngắn được do giai đoạn chuẩn bị và cắt stent tiến hành song song với các thì mổ mở.

- Số lượng bệnh nhân còn nhỏ và chưa theo dõi lâu dài

\section{KẾT LUÂ̂N}

Phương pháp phẫu thuật mở kết hợp dùng ống ghép lai sản xuất tại chỗ là hiệu quả kinh tế, điều trị tốt các trường hợp bệnh động mạch chủ bóc tách cấp tính phức tạp và nặng nề. Phương pháp này có thể nhân rộng cho các trung tâm tim mạch khác.

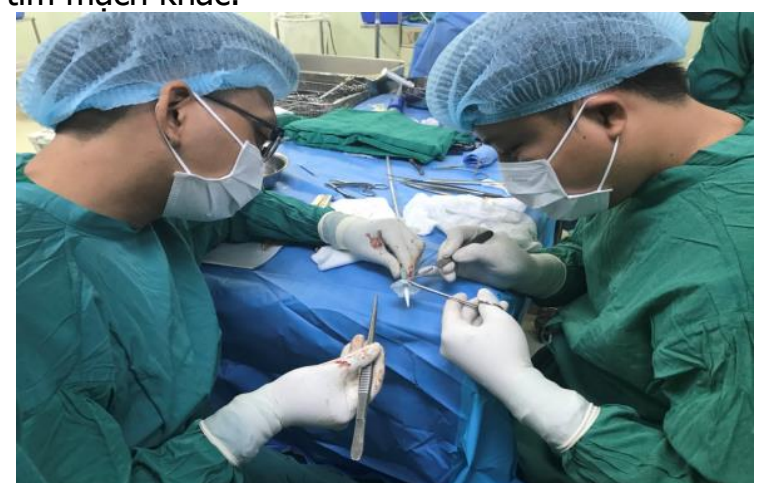

Hình 1. Cắt phân stent đầu tiên để tạo ống ghép lai

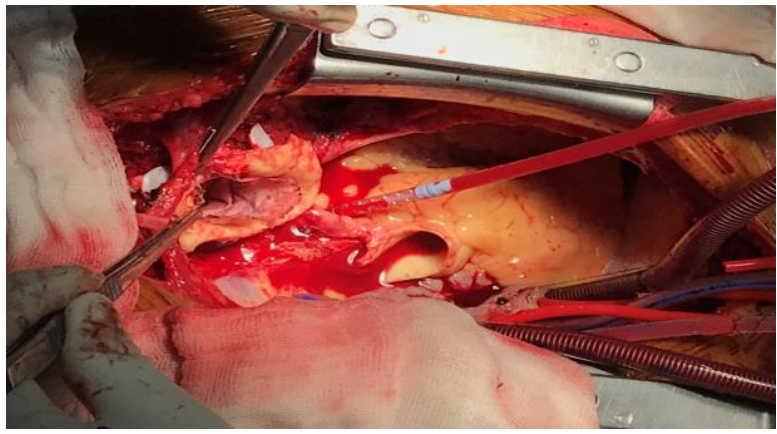

Hình 3. Vị trí đầu gân của ống ghép lai trùng với đầu xa động mạch chủ

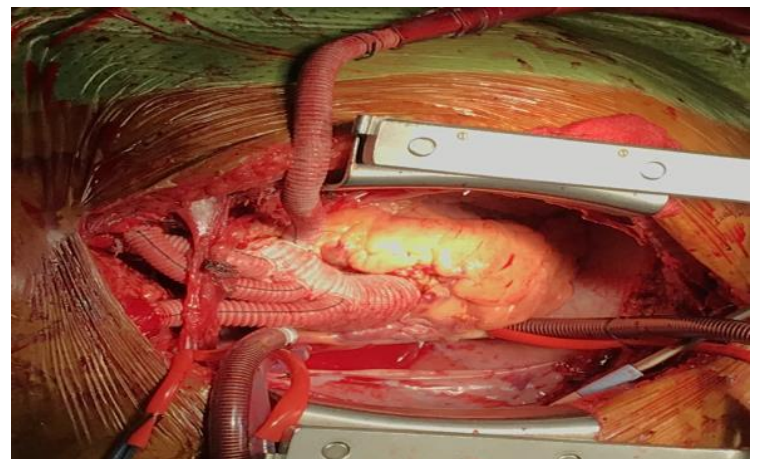

Hình 5. Động mạch chủ khi hoàn thành các miệnh nôi 


\section{TÀI LIÊU THAM KHẢO}

1. Y. Inoue, "Analysis of acute type A Dissection in Japan Registry of Aortic Dissection (JRAD)," Ann Thorac Surg, vol. 110, pp. 790-8, 2020.

2. M. R. K. Helder, "Regional and Temporal Trends in the Outcomes of Repairs for Acute Type A Aortic
Dissections," Ann Thorac Surg, vol. 109, pp. 2635, 2020.

3. S. J. Bozso, "Midterm Outcomes of the Dissected Aorta Repair Through Stent Implantation Trial," Ann Thorac Surg, vol. 111, pp. 463-71, 2021.

\section{PHỤC HÌNH TOÀN HÀM CHO BÊ̂NH NHÂN MÒN RĂNG NẶNG}

\section{TÓM TẮT}

Việc kiểm soát mài mòn răng, đặc biệt là mòn răng nặng đã trở thành một chủ đề ngày càng được quan tâm trong chuyên ngành Răng hàm mặt. Phục hình toàn hàm tác động đến chức năng và thẩm mỹ. Điều quan trọng trong phục hình toàn hàm là xác định đúng kích thước dọc khớp cắn và khoảng nghỉ khớp cắn. Cách tiếp cận có hệ thống để kiểm soát mòn răng giúp tạo tiên lượng thuận lợi, có thể dự đoán trước được. Đây là báo cáo 1 trường hợp lâm sàng bệnh nhẩn bi mòn răng nặng với đề xuất 1 qui trình phục toàn hàm đơn giản, khác biệt.

\section{SUMMARY \\ FULL- MOUTH RESTORATION FOR SEVERE WORN DENTITION PATIENT}

The control of tooth wear, especially heavy tooth wear, is a interesting topic in dentistry. full mouth restoration concern function and aesthetics. It is important in full-mouth restoration to determine the correct occlusal vertical dimension and inter maxillar rest space. A systematic approach controling dental wear provides a favorable, predictable prognosis. This is a report of a clinical case patient with severe worn dentition with a simple proposal procedure.

\section{GIỚl THIỆU}

Mòn răng là thuật ngữ chung sử dụng để mô tả sự mất mô cứng bề mặt của răng do các nguyên nhân khác ngoài sâu răng, chẫn thương hoặc do rối loạn phát triển, thường là do loạn năng khớp thái dương hàm, do sai sót trong điều trị, do thói quen ăn uống và sự thiếu hiểu biết về răng miệng.

Mòn răng là một quá trình sinh lý nhìn thây bằng mắt thường, không thể đảo ngược và tăng dần theo tuổi [1]. Mòn răng gây giảm hiệu suẫt nhai, gây chết tủy....

\footnotetext{
*Trường Đại Hoc Y Dước, ĐHQGHN

**Trướng Đại Học Y Hà Nội

Chịu trách nhiệm chính: Phạm Như Hải

Email: phamnhuhai@yahoo.com

Ngày nhận bài: 5.01.2021

Ngày phản biên khoa học: 25.2.2021

Ngày duyệt bài: 10.3.2021
}

\section{Phạm Như Hải*, Nguyễn Thị Như Trang**}

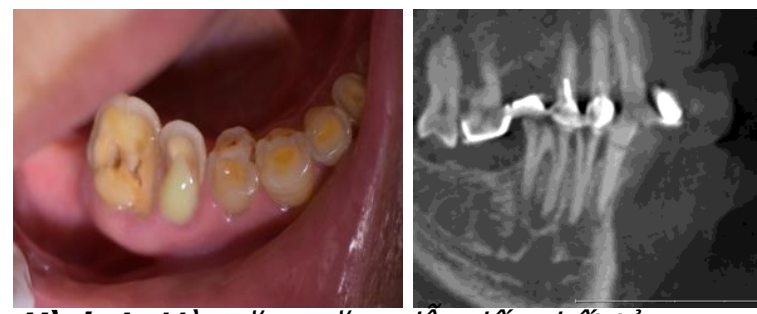

Hình 1: Mòn răng nặng dấn đến chết tủy, nang thân răng, dịch mú trào ra khi mở tủy răng 35 áp xe quanh chóp

Lambrechts và cộng sự. vào năm 1982, ước tính mức độ mất men theo chiêuu đứng do mài mòn sinh lý là khoảng 20-38 um mối năm [2]. Van't Spiiker và cộng sự nghiên cứu thây đàn ông mòn răng nặng hơn đàn bà, mòn răng nặng có thể gặp đến $3 \%$ ở người 20 tuổi và $17 \%$ ở người 70 tuổi. Mòn răng có thể được phân loại nguyên nhân thành cọ mòn, mài mòn và xói mòn, nhưng không phải lúc nào cũng có thể chẩn đoán phân biệt vì trong nhiêuu tình huống, có sự kết hợp của các quá trình này [3]. Trên lâm sàng khó có thể phân lập được một yếu tố căn nguyên duy nhất khi bệnh nhân có biểu hiện mòn răng, vì lý do này Eccles đề xuất vào năm 1982 dùng thuật ngữ "mất tổ chức bề mặt răng" (TSL: tooth surface loss) để ám chỉ tình trạng mòn răng do tất cả các yếu tố căn nguyên bất kể nguyên nhân chính xác của mài mòn đã được xác định hay không. Điêuu này bao gôm các yếu tố như chấn thương, yếu tổ phát triển của răng như tạo men - ngà không hoàn hảo và mòn răng do điều trị.

Trong thực hành lâm sàng hàng ngày, nhiêu bệnh nhân yêu câu làm phục hình để phục hôi khớp cắn do mòn nhiêu răng và mất răng vĩnh viễn sớm. Tuy nhiên, khoảng trống liên hàm thấp tạo ra thách thức cho việc điều trị phục hình cho bệnh nhân mòn răng vì không đủ khoảng cân thiết cho phục hình, dẫn đến hình thể của phục hình mỏng và thấp, không đủ khả năng lưu giữ và chịu lực.

Mục tiêu của phục hình toàn hàm không chỉ 